\title{
Development of Highly Functional Biomaterials by Decoupling and Recombining Material Properties
}

Citation for published version (APA):

Danoux, C., Sun, L., Kocer, G., Birgani, Z. T., Barata, D., Barralet, J., van Blitterswijk, C., Truckenmuller, R., \& Habibovic, P. (2016). Development of Highly Functional Biomaterials by Decoupling and Recombining Material Properties. Advanced Materials, 28(9), 1803-1808.

https://doi.org/10.1002/adma.201504589

Document status and date:

Published: 02/03/2016

DOI:

10.1002/adma.201504589

Document Version:

Publisher's PDF, also known as Version of record

Document license:

Taverne

Please check the document version of this publication:

- A submitted manuscript is the version of the article upon submission and before peer-review. There can be important differences between the submitted version and the official published version of record.

People interested in the research are advised to contact the author for the final version of the publication, or visit the DOI to the publisher's website.

- The final author version and the galley proof are versions of the publication after peer review.

- The final published version features the final layout of the paper including the volume, issue and page numbers.

Link to publication

\footnotetext{
General rights rights.

- You may freely distribute the URL identifying the publication in the public portal. please follow below link for the End User Agreement:

www.umlib.nl/taverne-license

Take down policy

If you believe that this document breaches copyright please contact us at:

repository@maastrichtuniversity.nl

providing details and we will investigate your claim.
}

Copyright and moral rights for the publications made accessible in the public portal are retained by the authors and/or other copyright owners and it is a condition of accessing publications that users recognise and abide by the legal requirements associated with these

- Users may download and print one copy of any publication from the public portal for the purpose of private study or research.

- You may not further distribute the material or use it for any profit-making activity or commercial gain

If the publication is distributed under the terms of Article $25 \mathrm{fa}$ of the Dutch Copyright Act, indicated by the "Taverne" license above, 


\title{
Development of Highly Functional Biomaterials by Decoupling and Recombining Material Properties
}

\author{
Charlène Danoux, Lanying Sun, Gülistan Koçer, Zeinab Tahmasebi Birgani, David Barata, \\ Jake Barralet, Clemens van Blitterswijk, Roman Truckenmüller, and Pamela Habibovic*
}

\begin{abstract}
Functional biomaterials are gaining importance in regenerative medicine as alternatives to classical treatments based on patient's own tissue, the limited supply of which is an important concern. ${ }^{[1-3]}$ A range of biomaterials exists, varying from natural to fully synthetic, from polymers to metals, from monolithic to complex composites and mixtures. Regardless the type or complexity, a biomaterial is always designed and produced in such a way that it elicits a desired biological function. ${ }^{[4]}$ Assessment of this function in response to the biomaterial should be reliable enough to serve as basis for further improvement, reverse engineering or combinatorial development of new materials. Recently, Murphy et al. asserted on the importance of co-varying inherent material properties in a controlled manner in order to obtain a better understanding of the relationship between individual properties. ${ }^{[3]}$ This, however, can only be achieved by decoupling individual properties of a material and understanding their sole effect on a biological process. In the current study, we undertook an attempt to shift the development of functional biomaterials so far requiring a materials processing-driven approach to now a design-driven one, increasing not only fundamental knowledge of the interactions between biomaterials and biological systems, but also practical possibilities to develop advanced biomaterials in terms
\end{abstract}

\footnotetext{
C. Danoux, L. Sun, G. Koçer, ${ }^{[+]}$Z. Tahmasebi Birgani, D. Barata, Prof. C. van Blitterswijk, Dr. R. Truckenmüller, Prof. P. Habibovic

Department of Tissue Regeneration

University of Twente

P.O. Box 217, $7500 \mathrm{AE}$, Enschede, The Netherlands

E-mail: p.habibovic@maastrichtuniversity.nl

L. Sun

Oral Implantology Center

Stomotology Hospital of Jinan

Jingliu Road 101, 250001 Jinan, China

L. Sun

Department of Oral Implantology

Shangdong University

Wenhuaxi Road 44-1, 250012 Jinan, China

Prof. J. Barralet

Faculty of Dentistry

McGill University

3640 University Street, Montreal, QC H3A 2B2, Canada

Prof. C. van Blitterswijk, Dr. R. Truckenmüller, Prof. P. Habibovic

MERLN Institute for Technology-Inspired Regenerative Medicine

Maastricht University

P.O. Box 616, 6200 MD Maastricht, The Netherlands

${ }^{[+]}$Present address: Laboratory of Bioinspired Molecular Engineering, MESA+ Institute for Nanotechnology, University of Twente, P.O. Box 217, $7500 \mathrm{AE}$, Enschede, The Netherlands

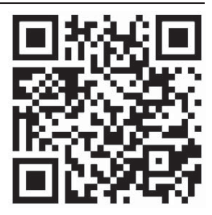

DOI: 10.1002/adma.201504589 of both functionality and applicability. To this end, we employed a range of processing techniques to first isolate individual properties and, upon investigating their sole effect on the biological function of clinically relevant human mesenchymal stromal cells (hMSCs), recombine them into improved or completely new functional biomaterials (Figure S1, Supporting Information). As a model material, we used calcium phosphate ( $\mathrm{CaP})$ ceramics, which are the most widely used synthetic bone graft substitutes, despite their intrinsic brittleness. ${ }^{[5]}$ Independent of the production method, i.e., precipitation, sol-gel technique or sintering, $\mathrm{CaP}$ ceramics are generally crystalline materials with distinct chemical composition, crystallinity, crystal/grain size, surface roughness, specific surface area, etc. These different properties are largely intertwined, and it is difficult, if not impossible, to change one without affecting the others by applying conventional production techniques. ${ }^{[6,7]}$ It is therefore particularly challenging to define the contribution of individual properties of $\mathrm{CaP}$ ceramics to a biological response as well as to produce such materials with well-defined and controlled properties. This is somewhat in contrast to other biomaterials, such as some (amorphous) polymers, which allow, to a certain extent, control over a single parameter without changing the others. ${ }^{[8-11]}$

While various properties of CaP-based biomaterials have been suggested to play a role in the processes related to bone formation and remodeling, ${ }^{[12,13]}$ no consensus has been reached yet as of how an optimal ceramic-based bone graft substitute should look like in a given application. To decouple the chemical effect of CaP (free calcium $\left(\mathrm{Ca}^{2+}\right.$ ) or inorganic phosphate $(\mathrm{Pi})$ ions in the vicinity of the surface, initial $\mathrm{CaP}$ as a substrate or re-precipitated CaP layer upon immersion in the cell culture medium) from the geometrical effect (crystal shape, surface micro- and nanostructure), a soft-embossing technique was used. ${ }^{[14]}$ Thereby, inverse replicas of the three types of crystals, i.e., needle-shaped dicalcium phosphate dihydrate/brushite $(\mathrm{BN})$ and needle- and plate-shaped dicalcium phosphate anhydrous/monetite (MN and MP) were first made in poly(dimethylsiloxane) (PDMS), a widely used elastomer in various applications including microfluidic devices ${ }^{[15,16]}$ and soft lithography. ${ }^{[17]}$ Subsequently, using this casting as a mold, geometrical analogs were made in cyclic olefin copolymer (COC), an amorphous transparent copolymer that is gaining attention for its optical clarity, biocompatibility, and structural strength. ${ }^{[18,19]} \mathrm{A}$ schematic of the entire process is shown in Figure 1A. Scanning electron microscopy (SEM) images of an original MN crystal and its analog in COC (Figure 1B1,C1, respectively) demonstrated that it was possible to reproduce the needle-like shape of the crystal in its original size. High-magnification SEM images (insets in Figure 1B1,C1) demonstrated 


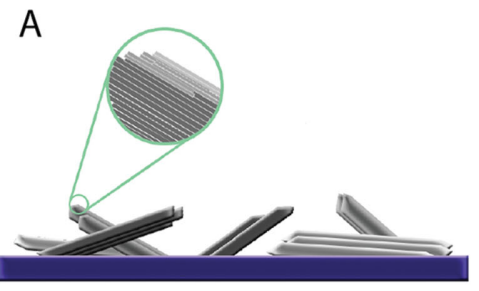

Dispensing crystals on the surface

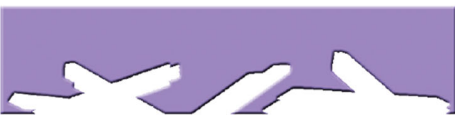

Cleaning and finishing of mold
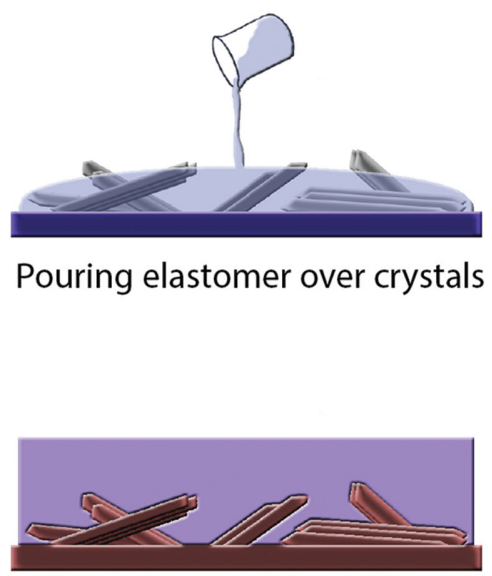

Embossing polymer substrate

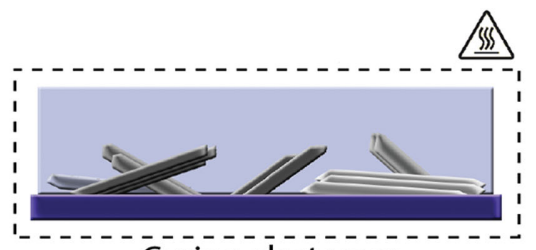

Curing elastomer

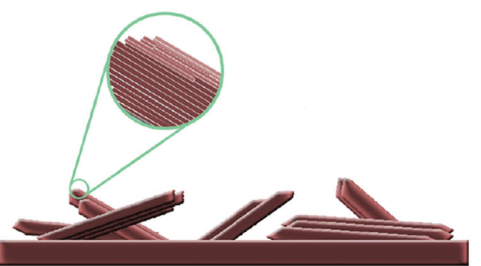

Crystal analog in polymer
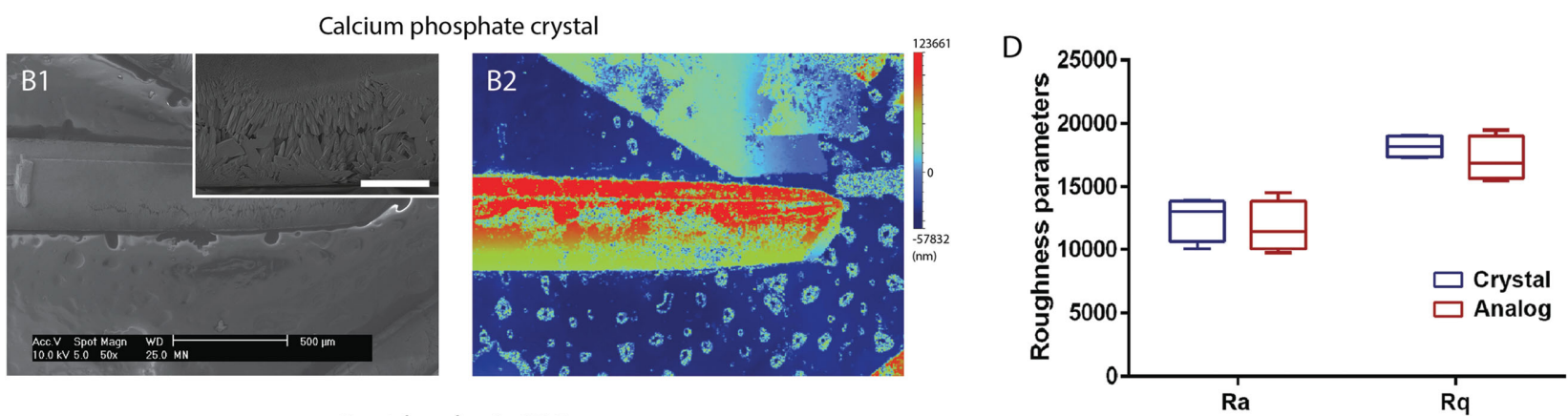

Crystal analog in $\mathrm{COC}$
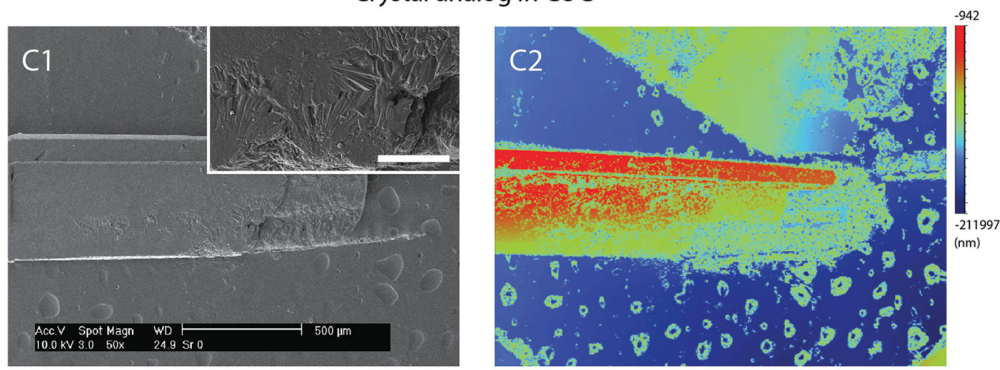

Figure 1. Decoupling chemical from geometrical properties of complex functional materials: A) schematic representation of CaP crystals-to-polymer replication process using soft embossing; B1) SEM image of CaP crystal (scale bar $=500 \mu \mathrm{m}$, scale bar inset $=100 \mu \mathrm{m}$ ) and B2) its roughness map; C1) SEM image of $\mathrm{CaP}$ crystal geometrical analog in COC (scale bar $=500 \mu \mathrm{m}$, scale bar inset $=100 \mu \mathrm{m}$ ) and C2) its roughness map; D) roughness quantification.

that also the flake-like sub-micrometer structure of the surface was reliably reproduced in the polymer substrate. Surface roughness mapping of the crystal and the analog using white light interferometry (Figure 1B2,C2, respectively) indeed confirmed a good transfer of the shape and structure features, and the quantification of the roughness (Figure 1D) shows minimal differences between the original crystal and the COC analog.

Therefore, the method used to transfer the structure of the crystals into the polymer proved to be reliable down to the sub-micrometer features of the crystal surface. These results showed that it was possible to separate the geometrical properties of $\mathrm{CaP}$ crystals from their chemical ones, resulting in materials with identical complex multiscale geometrical features, but completely different chemistry and other associated properties, such as mechanical strength and ductility. ${ }^{[20]}$ As a next step, and with the aim to retain these superior properties provided by the polymer as compared to the bulk CaP ceramic while recovering the chemical effect of $\mathrm{CaP}$, the surface of the crystal analogs of BN, MN and MP in COC was chemically modified with $\mathrm{CaP}$ by applying a biomimetic precipitation method at near-physiological $\mathrm{pH}$ and temperature. ${ }^{[21]}$ Alternative to this chemistry-recovery procedure, to develop a new material, the analog surface was chemically modified with a thin (maximum $35 \mathrm{~nm}$ thick) layer of titanium using DC sputtering. This artificial material combines the surface chemistry of titanium, the microstructure of a CaP, and the bulk mechanical properties of COC. 
Needle-shaped crystals had an elongated 3D geometry with a length ranging from 550 to $800 \mu \mathrm{m}$ and a width and height between 40 and $80 \mu \mathrm{m}$ for both crystal types. In contrast, MP presented a flat 3D geometry, with a relatively large area of about $2 \mathrm{~mm} \times 1 \mathrm{~mm}$ but a limited thickness below $50 \mu \mathrm{m}$. While the crystal surface of B crystals was fairly smooth, M crystals exhibited a more rough, flake-shaped surface, with an about 10 times larger specific surface area as compared to B crystals. Both coating methods resulted in a homogenous layer of $\mathrm{CaP}$ and titanium (Figure 2A and Figure S2, Supporting Information), respectively, with minimal effect on surface roughness, due to the low thickness and nanocrystalline or quasi-amorphous nature of the coatings (Figure 2A and Figure S3, Supporting Information).

To test whether decoupling and subsequent recombination of the properties of materials can be used as cues to control the biological response to these materials, hMSCs were cultured on uncoated and coated analogs in basic cell culture medium, not containing biological stimulators of osteogenic differentiation. All materials allowed attachment and growth of the cells (Figure S4, Supporting Information). Analysis of the expression of relevant osteogenic markers at mRNA level showed some effects of the geometrical features, i.e., needle- or platelike shape of the analog and surface sub-micrometer structure, however, the effect of the chemistry, in particular presence of $\mathrm{CaP}$ was more pronounced (Figure $2 \mathrm{~B}$ ). Indeed, upon reintroduction of $\mathrm{CaP}$ chemistry by deposition of the CaP layer on the surface of crystal analogs in COC, a significantly higher expression of the $\mathrm{Ca}^{2+}$ - and/or Pi ion-responsive genes bone morphogenetic protein-2 (BMP-2) and osteopontin (OP) was observed. Considering that the cells were cultured in basic medium, i.e., in the absence of biological stimulators of osteogenic differentiation, these results point at the importance of $\mathrm{Ca}^{2+}$ - and $\mathrm{Pi}$ ions in the process of differentiation and are in accordance with previous studies. ${ }^{[22-24]}$ Introduction of titanium also had a positive effect on the expression of OP as compared to the uncoated analogs, although this effect was not as strong as that of $\mathrm{CaP}$. Interestingly, the geometrical effect was best visible in the CaP-coated group, with plate-shaped analog and flat substrate showing a higher expression of BMP-2 than needle-shaped analogs. CaP-coated BN also showed a significantly lower OP expression than the flat coated substrate.

These data demonstrated that it is indeed possible to decouple and subsequently recombine individual properties of biomaterials to achieve a very similar biological effect while improving other properties. The results showed that the chemical component (i.e., presence of $\mathrm{CaP}$ ) overruled the effect of geometry on the osteogenic differentiation of hMSCs. To test whether this phenomenon is observed in other functional biomaterials as well, instead of producing geometrical analogs of $\mathrm{CaP}$ crystals and recovering the chemistry by surface coating, we successfully applied soft embossing to provide a widely used biomedical polymer, poly(lactic acid) (PLA) and its composite with nanosized hydroxyapatite (PLA/HA), as a source of $\mathrm{CaP}$, with defined microsized surface geometrical features (Figure 3A). All materials were successfully patterned by pits or pillars. Both topographies had an oval shape in the $x-y$ plane, with the long axis of about $20 \mu \mathrm{m}$, short axis of approximately $15 \mu \mathrm{m}$ and center-to-center distance between individual pits/ pillars of about $30 \mu \mathrm{m}$. Their depth/height was about $4 \mu \mathrm{m}$. These materials also allowed attachment and growth of hMSCs (Figure S5, Supporting Information). In accordance with the results obtained with geometrical analogs of $\mathrm{CaP}$ crystals, the results showed that hMSCs cultured on PLA/HA showed a considerably higher expression of OP and BMP-2 mRNA as compared to the culture on PLA without the ceramic, having identical topography (Figure 3B). Interestingly, alike in the case of crystal analogs, a mild effect of geometry was observed, only on PLA/HA samples. These data confirmed a more pronounced effect of $\mathrm{CaP}$ chemistry compared to geometrical features on the osteogenic differentiation of hMSCs. This effect of the presence of $\mathrm{CaP}$ could be explained as a direct influence of $\mathrm{Ca}^{2+}$. and $\mathrm{Pi}$ ion on cell differentiation as was discussed for coated crystal analogs. Nevertheless, the expected difference in stiffness between the polymer and the composite used here should also be taken into consideration, as suggested in a recent study by Mattei et al. ${ }^{25]}$

In this study, we presented a novel approach toward biomaterials development by first decoupling material properties, which are intertwined in most conventional materials, and by subsequently combining the desired properties into an improved material, for example with comparable bioinstructive potential, but better mechanical properties and potentially against lower costs. In addition to the examples provided here, this technique can be applied to a great diversity of other materials, including natural materials, like bone (Figure S6, Supporting Information). Moreover, other techniques can be applied within the same concept to isolate and combine properties and design new biomaterials. For example, 3D imaging of a (surface) structure of a functional material (e.g., by nanotomography) could be used as input to build similar structural features in other materials, using microfabrication techniques such as laser lithography based on two-photon polymerization. Photo- or UV nanoimprint lithography could be used as an alternative to thermal nanoimprinting. Electroplating/galvanoforming could be used as a chemical modification technique, or, instead of HA, other nanosized fillers with defined chemistry could be used to build composite materials. This modular approach toward biomaterials design that is not limited by the conventional processing parameters will not only generate new fundamental knowledge of the relationship between a material property and a biological response, but will also open new possibilities to develop functional biomaterials comprising instructive cues to regulate such a response. The freedom that such an approach offers, will potentially enable us to develop a spectrum of new biomaterials ranging from fully biomimetic on the one side, to materials with all rationally designed properties on the other side. It is expected that such a shift in the design approach will have an important societal impact by enabling development of materials for biomedical applications with improved properties and/or in a more cost-effective manner.

\section{Experimental Section}

Synthesis of CaP Crystals, Preparation of Geometrical Analogs in COC and Surface Chemistry Modification: B crystals were produced by mixing 
A

Brushite needles
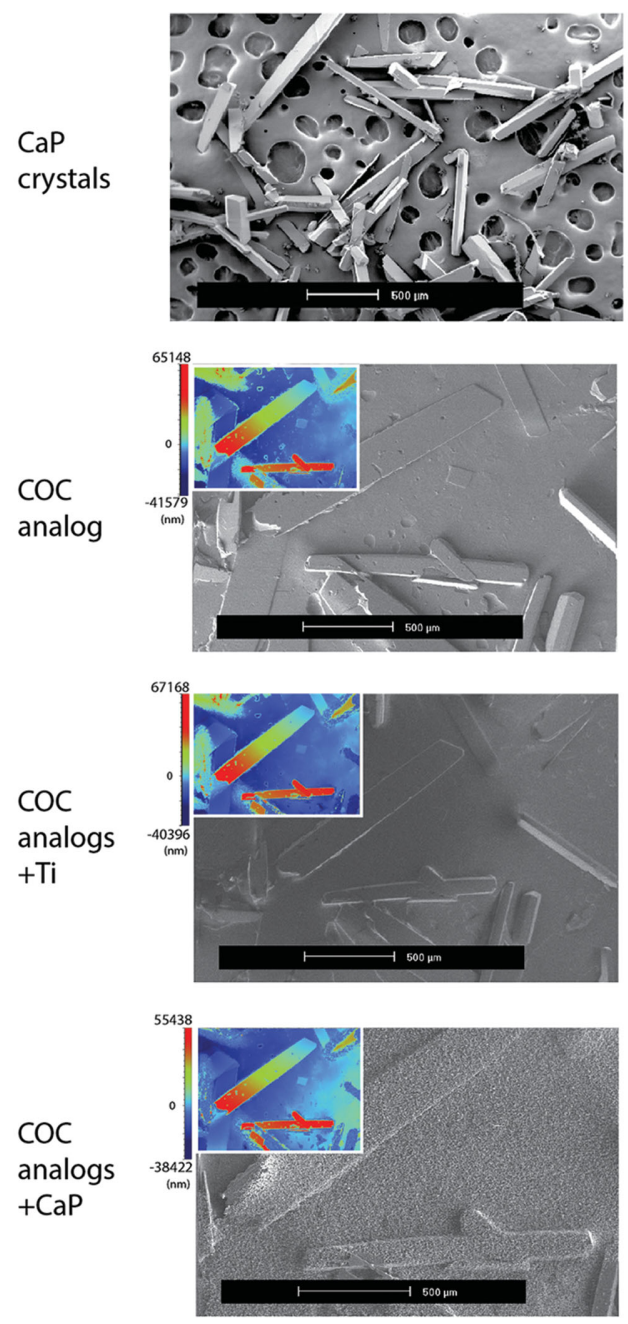

Monetite needles
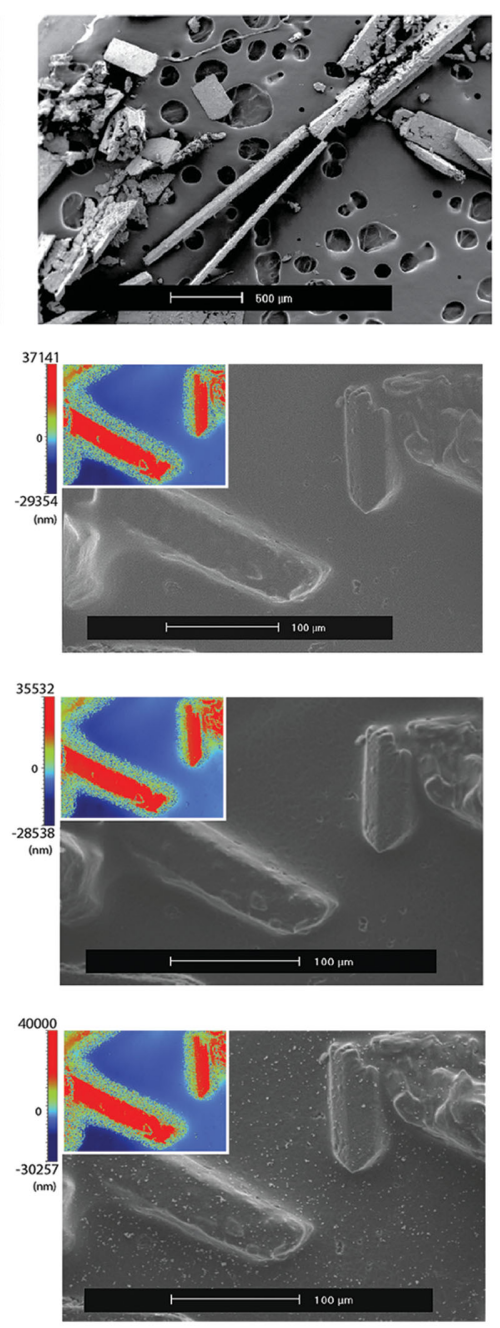

Monetite plates
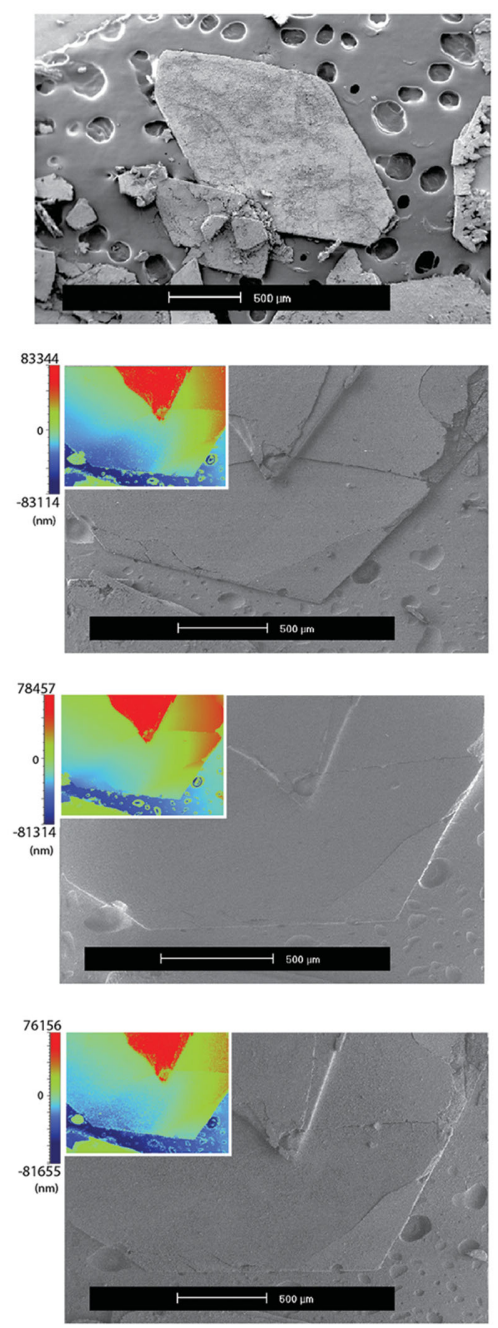

B
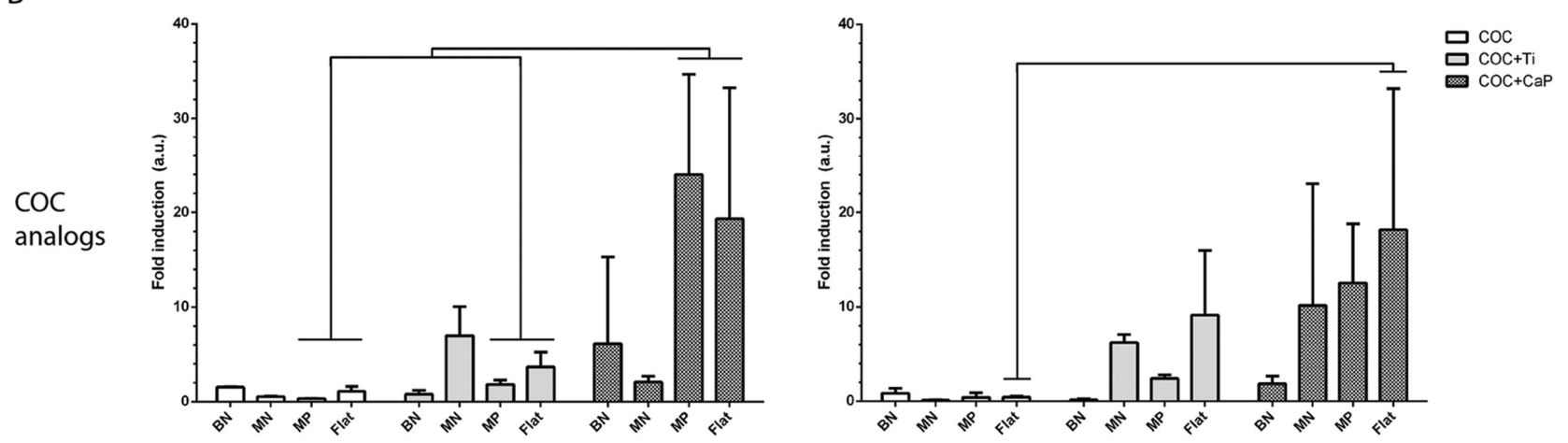

Figure 2. Design-driven approach toward functional biomaterials development using nanoimprinting and coating techniques: A) SEM microscopy images of BN, MN, and MP, precipitated from aqueous solutions (scale bar $=500 \mu \mathrm{m}$ ), SEM micrographs of geometrical analogs of the three crystal types in $\mathrm{COC}$ without chemical surface modification and coated with quasi-amorphous CaP or titanium (scale bar $=500 \mu \mathrm{m}$ for BN and MP and $100 \mu \mathrm{m}$ for MN) with, in insets, roughness maps at the same magnification and B) the mRNA expression of BMP-2 and OP, the two markers of osteogenesis, by hMSCs cultured for $14 \mathrm{~d}$ in basic cell culture medium. 

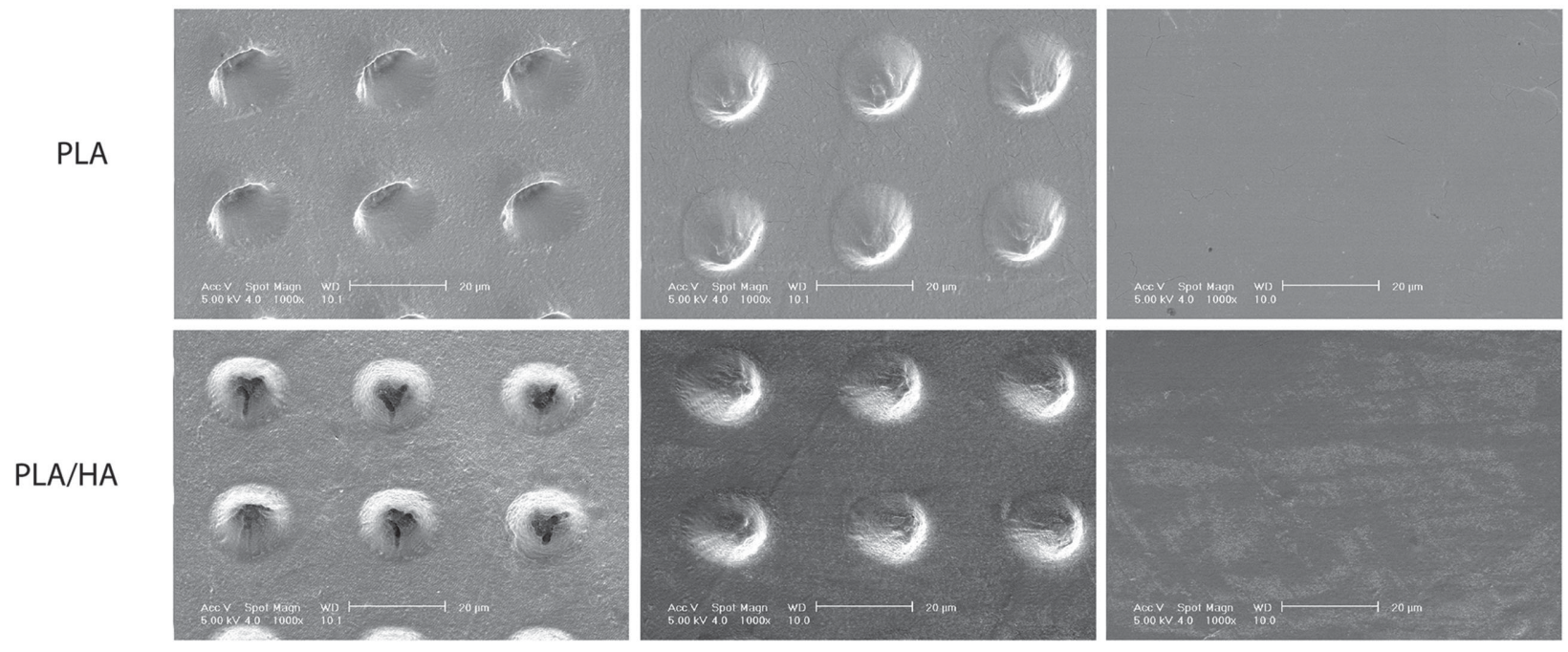

B
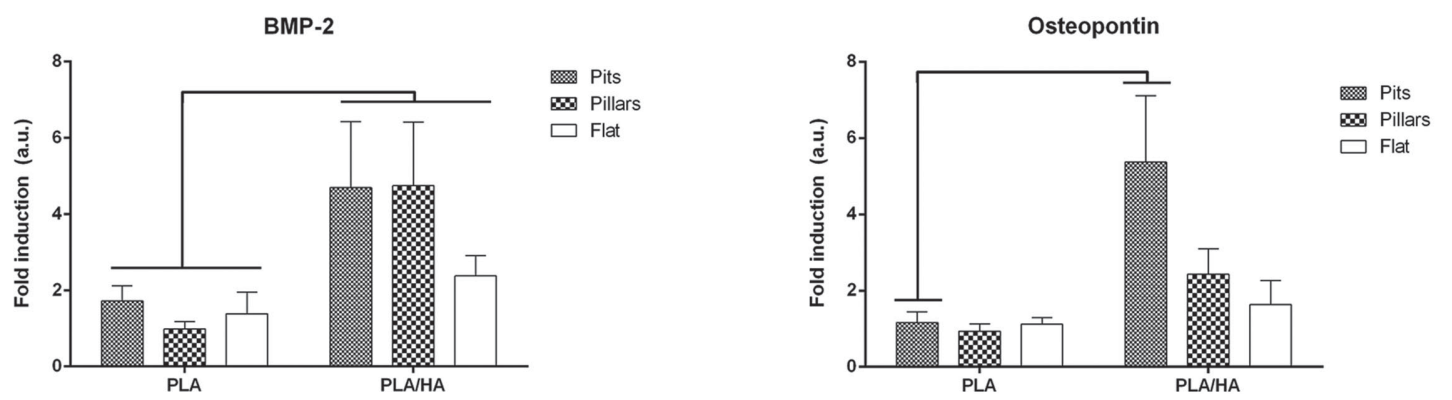

Figure 3. Design-driven approach toward functional biomaterials development using composite materials and nanoimprinting: A) SEM images of pits-patterned, pillars-patterned and flat PLA and PLA/HA (scale bar $=20 \mu \mathrm{m}$ ) and B) the mRNA expression of BMP-2 and OP by hMSCs cultured for $14 \mathrm{~d}$ in basic cell culture medium.

equal volumes of $0.25 \mathrm{M} \mathrm{CaCl}$ and $0.25 \mathrm{M}\left(\mathrm{NH}_{4}\right)_{2} \mathrm{HPO}_{4}$ solutions at $\mathrm{pH}$ 4.0 and keeping it at $40{ }^{\circ} \mathrm{C}$ for $48 \mathrm{~h}$. For $\mathrm{BN}$, upon mixing, the resulting solution was diluted to a final phosphate concentration of $0.2 \mathrm{M}$. M crystals were obtained by autoclaving B crystals at $120^{\circ} \mathrm{C}$ for 20 min.

The inverse PDMS molds were prepared by distributing and immobilizing the CaP crystals on a double-sided tape followed by casting of the silicone resin (Sylgard 184, Dow Corning, USA), mixed with the curing agent (Sylgard 184, Dow Corning, USA) at a 10:1 ratio, over the master structures, and by incubation at room temperature (RT) for $2 \mathrm{~d}$ and subsequently at $50{ }^{\circ} \mathrm{C}$ overnight to facilitate polymerization. After polymerization, molds were cleaned with $6 \mathrm{~m} \mathrm{HCl}$ solution and deionized water. Geometrical analogs of the crystals were produced by hot embossing of the PDMS molds onto a COC film (kindly provided by TOPAS, Frankfurt, Germany) with a thickness of $300 \mu \mathrm{m}$ at $130^{\circ} \mathrm{C}$ for $90 \mathrm{~min}$. To introduce chemistry changes while retaining the surface structure, crystal analogs in $\mathrm{COC}$ were coated with either titanium by DC sputtering at $200 \mathrm{~W}$ (Sputterke, TCO, University of Twente, The Netherlands), which resulted in a titanium layer with a maximum thickness of $35 \mathrm{~nm}$, or with CaP by immersion in a simplified fivefold concentrated simulated body fluid ${ }^{[2]]}$ for $12 \mathrm{~h}$ at $37^{\circ} \mathrm{C}$, following air plasma (Plasma sterilizer, PDC-002, Harrick Scientific, USA) treatment for $6 \mathrm{~s}$. After the coating process, samples were thoroughly washed with demineralized water and dried at RT. In order to examine the efficiency of the replication technique, a sample of MN crystals was selected to analyze surface morphology using SEM and to perform roughness quantification using white light interferometry (Contour GT-I, Bruker, USA).
Preparation and Surface Microstructuring of PLA/HA Composites: PLA/HA composite consisting of $50 \mathrm{wt} \%(55000-59000 \mathrm{Da}$ ) poly(D,L-lactic acid) (PLA) (ANaBior, France) and 50 wt\% in-house synthesized HA powder was prepared using extrusion as described previously. ${ }^{[26,27]}$ The same extrusion procedure was used to prepare the control materials made of PLA without $\mathrm{HA}$. The materials were then shaped into pellets with a diameter of $10 \mathrm{~mm}$ using a metal frame mold and a heating press at $120{ }^{\circ} \mathrm{C}$ and $30 \mathrm{kN}$ for 5 min. Inverse PDMS molds of the pits topography were produced by pouring the same silicone elastomer resin as described for crystal analogs over a stainless-steel master with pits produced using pulsed femtosecond laser micromachining (Lightmotif, Enschede, The Netherlands), followed by incubation at RT for $2 \mathrm{~d}$ and subsequently at $50^{\circ} \mathrm{C}$ overnight to facilitate polymerization. Upon removal, the PDMS negative replica, i.e., with pillars was used to produce a second PDMS replica (with pits) using the same method. Both PDMS replicas were subsequently used as molds to imprint surfaces of composite and polymer pellets by hot embossing at $120^{\circ} \mathrm{C}$ for 10 and 6 min for composite and polymer, respectively. Samples embossed with flat PDMS mold served as control. The surfaces were examined using an SEM equipped with an energy dispersive $\mathrm{X}$-ray spectroscopy module (EDS) (Apollo X, Ametek).

In vitro Cell Culture and Assessment of Osteogenic Differentiation: Bone marrow aspirates from healthy patients were obtained after written informed consent, and hMSCs were isolated and expanded as described previously. ${ }^{[28,29]}$ Crystal analogs in COC without additional coating were treated with air plasma for 1 min prior to further sterilization. Individual samples of the analogs of each crystal type, without or with titanium 
or $\mathrm{CaP}$ coating and surface patterned and flat PLA and PLA/HA pellets were placed in ultralow attachment 24 well plates and fixed with $O$ rings with suitable diameter. The samples were then sterilized with either $70 \%$ and $100 \%$ ethanol (for crystal analogs) or with $70 \%$ isopropyl alcohol (for PLA and PLA/HA), and, following complete evaporation, washed with sterile PBS. They were then preconditioned in proliferation medium ( $\alpha$-minimal essential medium (Gibco), 10\% fetal bovine serum (Lonza), $0.2 \times 10^{-3} \mathrm{M}$ ascorbic acid (Sigma Aldrich), $2 \times 10^{-3} \mathrm{M}$ L-glutamine (Gibco), 100 units $/ \mathrm{mL}$ penicillin (Gibco), $100 \mu \mathrm{g} \mathrm{mL} \mathrm{m}^{-1}$ streptomycin (Gibco) $1 \mathrm{ng} \mathrm{mL}^{-1}$ basic fibroblast growth factor (FGF) (Fisher Scientific)) overnight in a humidified atmosphere with $5 \% \mathrm{CO}_{2}$ prior to cell seeding.

To investigate the osteogenic gene expression, 200000 cells were seeded on each crystal analog sample and 10000 cells on each PLA and PLA/HA sample. The cells were cultured in basic medium (proliferation medium without FGF) for up to $14 \mathrm{~d}$, with refreshment of medium every 2-3 d. RNA isolation and cDNA synthesis were performed as described previously. ${ }^{[23]}$ Quantitative real-time polymerase chain reaction (qPCR) analysis was performed for a set of markers, including BMP-2 and OP (Table S1, Supporting Information) and fold induction was calculated using the comparative $\triangle C T$ method, upon normalization of $C T$ values to the Glyceraldehyde 3-phosphate dehydrogenase (GAPDH) housekeeping gene.

Statistical Analysis: Statistical analysis was performed using one-way analysis of variance (ANOVA) with a Bonferroni posthoc test. The level of significance was set at $p<0.05$. All quantitative data presented are expressed as mean \pm standard deviation.

\section{Supporting Information}

Supporting Information is available from the Wiley Online Library or from the author.

\section{Acknowledgements}

Financial support by the TeRM Smart Mix Program of the Netherlands Ministry of Education, Culture and Science (CD), the Sci-Tech Development Program of Jinan City (201221055), and the Medical SciTech Development Program of Jinan City (2008-30) (LS), the research program of the BioMedical Materials institute, co-funded by the Dutch Ministry of Economic Affairs, Agriculture and Innovation (Project P2.04 BONE-IP) (ZTB), and The Netherlands Institute for Regenerative Medicine (DB) is acknowledged. This project has been in part made possible with the support of the Dutch Province of Limburg. Daniel de Melo Pereira is acknowledged for his help with the figures.

Received: September 17, 2015

Revised: October 30, 2015

Published online: December 22, 2015

[1] M. E. Furth, A. Atala, M. E. Van Dyke, Biomaterials 2007, 28, 5068.

[2] J. A. Hunt, Nat. Mater. 2008, 7, 617.

[3] W. L. Murphy, T. C. McDevitt, A. J. Engler, Nat. Mater. 2014, 13, 547.

[4] D. Williams, Essential Biomaterials Science, Vol. 1, Cambridge University Press, Cambridge, UK 2014, pp. 17-26.
[5] S. Dorozhkin, BIO 2011, 1, 1

[6] P. Habibovic, J. E. Barralet, Acta Biomater. 2011, 7, 3013.

[7] H. Lapczyna, L. Galea, S. Wust, M. Bohner, S. Jerban, A. Sweedy, N. Doebelin, N. Van Garderen, S. Hofmann, G. Baroud, R. Muller, B. Von Rechenberg, Eur. Cells Mater. 2014, 28, 299.

[8] S. Y. Chou, P. R. Krauss, P. J. Renstrom, J. Vac. Sci. Technol. B 1996, $14,4129$.

[9] A. Engler, L. Bacakova, C. Newman, A. Hategan, M. Griffin, D. Discher, Biophys. J. 2004, 86, 617.

[10] P. Murugan, M. Krishnamurthy, S. N. Jaisankar, D. Samanta, A. B. Mandal, Chem. Soc. Rev. 2015, 44, 3212.

[11] H. V. Unadkat, M. Hulsman, K. Cornelissen, B. J. Papenburg, R. K. Truckenmuller, A. E. Carpenter, M. Wessling, G. F. Post, M. Uetz, M. J. Reinders, D. Stamatialis, C. A. Van Blitterswijk, J. De Boer, Proc. Natl. Acad. Sci. USA 2011, 108, 16565.

[12] F. Barrere, C. A. Van Blitterswijk, K. De Groot, Int. J. Nanomed. 2006, 1, 317.

[13] A. M. Barradas, H. Yuan, C. A. Van Blitterswijk, P. Habibovic, Eur. Cells Mater. 2011, 21, 407.

[14] A. P. Russo, D. Apoga, N. Dowell, W. Shain, A. M. P. Turner, H. G. Craighead, H. C. Hoch, J. N. Turner, Biomed. Microdevices 2002, 4, 277.

[15] C. S. Effenhauser, G. J. Bruin, A. Paulus, M. Ehrat, Anal. Chem. $1997,69,3451$.

[16] D. C. Duffy, J. C. McDonald, O. J. Schueller, G. M. Whitesides, Anal. Chem. 1998, 70, 4974

[17] Y. N. Xia, G. M. Whitesides, Angew. Chem. Int. Ed. 1998, 37, 550.

[18] W. D. Niles, P. J. Coassin, Assay Drug Dev. Technol. 2008, 6, 577.

[19] P. S. Nunes, P. D. Ohlsson, O. Ordeig, J. P. Kutter, Microfluid. Nanofluid. 2010, 9, 145.

[20] A. Kasgoz, D. Akin, A. I. Ayten, A. Durmus, Composites, Part B 2014, 66, 126.

[21] P. Habibovic, F. Barrere, C. A. Van Blitterswijk, K. De Groot, P. Layrolle, J. Am. Ceram. Soc. 2002, 85, 517

[22] A. M. Barradas, H. A. Fernandes, N. Groen, Y. C. Chai, J. Schrooten, J. Van de Peppel, J. P. Van Leeuwen, C. A. Van Blitterswijk, J. De Boer, Biomaterials 2012, 33, 3205.

[23] C. Danoux, D. C. Bassett, Z. Othman, A. I. Rodrigues, R. L. Reis, J. Barralet, C. A. Van Blitterswijk, P. Habibovic, Acta Biomater. 2015.

[24] Y. R. Shih, Y. Hwang, A. Phadke, H. Kang, N. S. Hwang, E. J. Caro, S. Nguyen, M. Siu, E. A. Theodorakis, N. C. Gianneschi, K. S. Vecchio, S. Chien, O. K. Lee, S. Varghese, Proc. Natl. Acad. Sci. USA 2014, $111,990$.

[25] G. Mattei, C. Ferretti, A. Tirella, A. Ahluwalia, M. Mattioli-Belmonte, Sci. Rep. 2015, 5, 10778

[26] D. Barbieri, H. Yuan, X. Luo, S. Fare, D. W. Grijpma, J. D. De Bruijn, Acta Biomater. 2013, 9, 9401.

[27] C. B. Danoux, D. Barbieri, H. Yuan, J. D. De Bruijn, C. A. Van Blitterswijk, P. Habibovic, Biomaterials 2014, 4, e27664.

[28] S. K. Both, A. J. C. Van der Muijsenberg, C. A. Van Blitterswijk, J. De Boer, J. D. De Bruijn, Tissue Eng. 2007, 13, 3.

[29] H. Fernandes, A. Mentink, R. Bank, R. Stoop, C. Van Blitterswijk, J. De Boer, Tissue Eng., Part A 2010, 16, 1693. 